\title{
Assessment of the Receptivity of Dengue Vector Breeding through Pre- and Post-Monsoon Vector Surveillance at Some International Airports in India
}

\author{
SN Sharma, Sujeet K Singh \\ National Centre for Disease Control, 22 Sham Nath Marg, Delhi, India. \\ DOI: https://doi.org/10.24321/0019.5138.202135
}

\section{I $\quad \mathbf{N} \quad \mathbf{F} \quad \mathbf{O}$}

\section{Corresponding Author:}

SN Sharma, National Centre for Disease Control, 22 Sham Nath Marg, Delhi, India.

E-mail Id:

drsns.nvbdcp@gmail.com

Orcid Id:

https://orcid.org/0000-0001-8569-1661

How to cite this article:

Sharma SN, Singh SK. Assessment of the Receptivity of Dengue Vector Breeding through Pre- and Post-Monsoon Vector Surveillance at Some International Airports in India. J Commun Dis. 2021;53(3):16-22.

Date of Submission: 2021-08-09

Date of Acceptance: 2021-08-23

\author{
$\begin{array}{llllllll}\mathbf{A} & \mathbf{B} & \mathbf{S} & \mathbf{T} & \mathbf{R} & \mathbf{A} & \mathbf{C} & \mathbf{T}\end{array}$
}

\begin{abstract}
As per the International Health Regulations (2005), all the International airports and seaports are to be kept free from the risk of infection through any pathogen transmitted by vectors, thereby resulting in public health hazard. Therefore, all the international airports and seaports premises are to be kept free from any vector breeding along with the 400 perimeter areas surrounding the airports and seaports. To assess the receptivity of Vector breeding i.e. Aedes aegypti (Vector for Dengue, Yellow fever, Zika and Chikunguniya), the entomological teams from the Centre for Medical Entomology and Vector Control, NCDC have been undertaking vector surveillance activities (Pre \& Post Monsoon) at POE's of some International Airports \& Seaports. The vector surveillance is being done on regular basis and the findings are being shared with the respective authorities for undertaking immediate control measures. From the years 2015 to 2020, Dengue vector surveillance activities were carried out at 10 international airports including 400 meters peripheral areas during pre- and post-monsoon periods. An attempt has been made to describe the receptivity of the airports with the key findings with entomological indices with regard to the prevention and control of dengue vector and for proper planning to undertaking timely control measures to regulate the International Health Regulations in the respective international airports. Such studies on the assessment of receptivity would help the local airport health authorities in understanding the breeding potential habitats of Aedes vector and planning the appropriate vector control strategy in the respective areas.
\end{abstract}

Keywords: Dengue, IHR, Monsoon Vector Surveillance, Point of Entry, Vector Borne Diseases 


\section{Introduction}

Aedes aegypti mosquitoes are known to transmit arboviral diseases to man in both rural and urban areas. International Airports are important points of entry for arbo-viral infections from endemic to non-endemic country due to large scale international travellers influx round the year. The International Health Regulations (IHR), 1969 laid emphasis on the national governments to keep all the International airports/seaports and peripheral areas up to 400 meters free from Aedes aegypti mosquitoes (adult as well as immature stages) and the mosquito vectors of malaria and other diseases of epidemiological significance, being vulnerable entry points. The purpose of IHR is "to ensure maximum security against the international spread of disease with a minimum interference with the world traffic" ${ }^{1,2}$ In India, lot of emphasis has been given to enforce anti-mosquito measures to keep its international airports free from adult and immature stages of Aedes aegypti and other Stegomiya spp.

Dengue vector control envisages reduction of aquatic stages of vector species through source reduction by eliminating breeding habitats. The eradication of Aedes aegypti $(\mathrm{L})$ from Brazil was achieved during the 1930s following a highly organized surveillance. ${ }^{3}$ Similarly, other larval control with more specific goals has resulted in reduction of dengue transmission in Australia, Indonesia, Thailand and Brazil. In India, Aedes aegypti is a known principal vector of dengue fever while dengue virus has also been recently detected in Aedes albopictus. The entomological surveillance for Aedes aegypti has also been carried out in the past at international airports and seaports for dengue $\&$ chikungunya. ${ }^{4-9}$

An attempt has been made to assess the receptivity of Vector breeding i.e. Aedes aegypti (Vector for Dengue, Yellow fever, Zika and Chikunguniya) at some international airports. The entomological teams from the Centre for Medical Entomology \& Vector Control, NCDC have been visiting the areas for undertaking vector surveillance activities during Pre \& Post Monsoon at POE's of some International Airports \& Seaports. The entomological indices were calculated with the search of preferential breeding habitats inside and outside the airports. The findings of vector surveillance were shared on regular basis with the respective authorities for undertaking immediate control measures. Threshold on vector population or entomological indices may be always considered zero at the International airports as per IHR (2005). Information collected during Dengue vector surveillance activities has been analyzed for the years 2015 to 2020 after regular visits to 10 international airports including 400 meters peripheral areas during pre and post monsoon periods. Based on the findings, an attempt has been made to describe the receptivity of the airports with the key findings to assess potential risk of disease transmission and to take measures with regard to the prevention and control of dengue vector to regulate the International Health Regulations in the respective international airports.

\section{Methodology}

Surveys of Aedes (Stegomyia) breeding places were carried out in airport premises and 400 meters perimeter of the International airport from 2015 to 2020. The standard entomological surveillance tools were applied during the filed visits. The larvae collected from different types of containers were reared in 12 " $\times 12$ " mosquito cages to confirm the species identity of Aedes (Stegomyia) mosquitoes. The mosquito larvae were collected from different types of containers holding fresh water and were reared in cages measuring $30 \times 30 \mathrm{~cm}$ by putting them in beakers $250 \mathrm{~mL}$ capacity at room temperature $25 \pm 5$ ㅇ $\mathrm{C}$ and $65 \pm 5 \%$ relative humidity $(\mathrm{RH})$. The adults emerged from larvae/pupae were identified. The data collected so for breeding places of the Aedes, was analyzed and various indices like House Index $(\mathrm{HI})$, Container Index $(\mathrm{Cl})$ and Breteau Index (BI) were calculated. The Premise Index (PI) was taken up for the premise area of the airports.

\section{Key Observations}

The status of compiled reports on pre-monsoon vector surveillance after the visits at POE's of International Airports during 2015 - 2020 is given in Table 1.

Amritsar Airport: The entomological indices i.e. $\mathrm{PI}, \mathrm{Cl}$ and BI have been zero inside the airport from 2015 to 2019. However, House Index (HI), Container Index (Cl) and Breteau Index (BI) have been 2.0, 1.3, 2.0 and 4.0, 2.7, 5.0 in the years 2018 \& 2019 respectively. This may be due to the newly developed area and in the out skirt of the town and the residential areas have grown up near the airport now.

Thiruvanthapuram Airport: Inside the airport, during Aedes vector surveillance from 2015 to 2019, the premise index (PI) ranged between 4.0 to 14.58 with Container Index (CI) ranged from 3.0 to 25.0 and Breteau index has been between 4.0 to 41.67 . Outside the airport, the house index $(\mathrm{HI})$ ranged between 4.0 to 12.0 with Container Index $(\mathrm{Cl})$ ranged from 3.6 to 25.6 and Breteau index has been between 5.0 to 24.0

Goa Airport: Inside the airport, during Aedes vector surveillance from 2015 to 2019, the premise index (PI) ranged between 0 to 48.1 with Container Index $(\mathrm{Cl})$ ranged from 0 to 59.4 and Breteau index has been between 0 to 222.2. Outside the airport, the house index $(\mathrm{HI})$ ranged between 0 to 11.5 with Container Index $(\mathrm{Cl})$ ranged from 0 to 6.8 and Breteau index has been between 0 to 16.7. 
Table I.Compiled Data of Entomological Indices Recorded from Different Airports during Pre-monsoon Period (2015-2020)

\begin{tabular}{|c|c|c|c|c|c|c|c|}
\hline \multirow{3}{*}{ Name of airport } & \multirow{3}{*}{ Year } & \multicolumn{6}{|c|}{ Pre-monsoon } \\
\hline & & \multicolumn{3}{|c|}{ Entomological indices (Inside) } & \multicolumn{3}{|c|}{ Entomological indices (Outside) } \\
\hline & & PI & $\mathrm{Cl}$ & BI & HI & $\mathrm{Cl}$ & BI \\
\hline \multirow{6}{*}{ Amritsar Airport } & 2015 & 0 & 0 & 0 & 0 & 0 & 0 \\
\hline & 2016 & 0 & 0 & 0 & 0 & 0 & 0 \\
\hline & 2017 & 0 & 0 & 0 & 0 & 0 & 0 \\
\hline & 2018 & 0 & 0 & 0 & 2.0 & 1.3 & 2.0 \\
\hline & 2019 & 0 & 0 & 0 & 4.0 & 2.7 & 5.0 \\
\hline & 2020 & \multicolumn{6}{|l|}{ Not Done due to COVID-19 } \\
\hline \multirow{6}{*}{$\begin{array}{c}\text { Thiruvanthpuram } \\
\text { Airport }\end{array}$} & 2015 & 14.29 & 10.0 & 14.29 & - & - & - \\
\hline & 2016 & 14.58 & 11.05 & 41.67 & 12.0 & 3.60 & 12 \\
\hline & 2017 & 6.3 & 4.4 & 10.6 & 11.0 & 11.4 & 24.0 \\
\hline & 2018 & 4.2 & 25.0 & 25.0 & 4.0 & 6.4 & 5.0 \\
\hline & 2019 & 4.0 & 3.0 & 4.0 & 10.0 & 25.6 & 11.0 \\
\hline & 2020 & \multicolumn{6}{|l|}{ Not Done due to COVID-19 } \\
\hline \multirow{6}{*}{ Goa Airport } & 2015 & 2.4 & 0 & 0 & 4.0 & 0 & 0 \\
\hline & 2016 & 0 & 0 & 0 & 0 & 0 & 0 \\
\hline & 2017 & Not Done & & & & & \\
\hline & 2018 & 48.1 & 59.4 & 222.2 & 6.0 & 4.8 & 6.0 \\
\hline & 2019 & 0 & 0 & 0 & 11.5 & 6.8 & 16.7 \\
\hline & 2020 & \multicolumn{6}{|l|}{ Not Done due to COVID-19 } \\
\hline \multirow{6}{*}{ Cochin Airport } & 2015 & 11.76 & 1.21 & 11.76 & 0 & 4.12 & 0 \\
\hline & 2016 & 14.2 & 9.67 & 35.21 & 22.0 & 6.23 & 22.0 \\
\hline & 2017 & 7.1 & 13.5 & 26.1 & 13.0 & 21.0 & 34.0 \\
\hline & 2018 & 0 & 0 & 0.0 & 20.0 & 24.5 & 25.0 \\
\hline & 2019 & 0 & 0 & 0 & 2.0 & 5.7 & 2.0 \\
\hline & 2020 & \multicolumn{6}{|l|}{ Not done due to COVID-19 } \\
\hline \multirow{4}{*}{ Calicut Airport } & 2017 & 0. & 0 & 0 & 10.7 & 11.8 & 14.0 \\
\hline & 2018 & 4.8 & 1.9 & 9.5 & 0 & 0 & 0 \\
\hline & 2019 & 15.4 & 5.4 & 15.4 & 0 & 0 & 0 \\
\hline & 2020 & \multicolumn{6}{|l|}{ Not done due to COVID-19 } \\
\hline \multirow{4}{*}{ Jaipur Airport } & 2017 & $\begin{array}{c}\text { New airport included in } \\
\text { year } 2018\end{array}$ & & & & & \\
\hline & 2018 & 17.3 & 1.1 & 21.7 & 8.0 & 4.0 & 9.0 \\
\hline & 2019 & 0 & 0 & 0 & 9.0 & 7.6 & 9.0 \\
\hline & 2020 & \multicolumn{6}{|l|}{ Not done due to COVID-19 } \\
\hline \multirow{4}{*}{$\begin{array}{c}\text { New Mangalore } \\
\text { Airport }\end{array}$} & 2017 & $\begin{array}{c}\text { New airport included in } \\
\text { year } 2018\end{array}$ & & & & & \\
\hline & 2018 & 4.3 & 3.6 & 8.7 & 5.0 & 8.0 & 9.0 \\
\hline & 2019 & 0 & 0 & 0 & 4.0 & 19.4 & 6.0 \\
\hline & 2020 & \multicolumn{6}{|l|}{ Not done due to COVID-19 } \\
\hline
\end{tabular}




\begin{tabular}{|c|c|c|c|c|c|c|c|}
\hline \multirow{4}{*}{ Tirupati Airport } & 2017 & $\begin{array}{c}\text { New airport included in } \\
\text { year } 2018\end{array}$ & & & & & \\
\hline & 2018 & 11.1 & 1.4 & 11.1 & 62.5 & 9.9 & 150.0 \\
\hline & 2019 & 0 & 0 & 0 & 18.2 & 2.8 & 27.3 \\
\hline & 2020 & Not done due to COVID-19 & & & & & \\
\hline \multirow{6}{*}{ Bangalore Airport } & 2015 & 15 & 7.80 & 82.50 & 0 & 0 & 0 \\
\hline & 2016 & 6.38 & 0.96 & 6.38 & 31.6 & - & - \\
\hline & 2017 & 12.0 & 10.2 & 29.3 & - & 10.7 & 52.3 \\
\hline & 2018 & 5.1 & 6.3 & 7.7 & 12.0 & 13.6 & 40.0 \\
\hline & 2019 & 8.9 & 8.3 & 52.8 & 89.5 & 10.9 & 25.8 \\
\hline & 2020 & Not done due to COVID-19 & & & & & \\
\hline \multirow{6}{*}{ Trichy Airport } & 2015 & 0 & 0 & 0 & 0.71 & 0.49 & 0.71 \\
\hline & 2016 & Not done & & & & & \\
\hline & 2017 & 10.0 & 25.0 & 10.0 & 12.6 & 5.8 & 13.6 \\
\hline & 2018 & 10.0 & 5.3 & 6.7 & 3.4 & 2.7 & 4.9 \\
\hline & 2019 & 14.3 & 14.3 & 14.3 & 11.1 & 7.9 & 17.3 \\
\hline & 2020 & Not done due to COVID-19 & & & & & \\
\hline
\end{tabular}

Cochin Airport: Inside the airport, during Aedes vector surveillance from 2015 to 2019, the premise index (PI) ranged between 0 to 11.76 with Container Index $(\mathrm{Cl})$ ranged from 0 to 13.5 and Breteau index has been between 0 to 35.21. Outside the airport, the house index $(\mathrm{HI})$ ranged between 0 to 22.0 with Container Index $(\mathrm{Cl})$ ranged from 4.12 to 24.5 and Breteau index has been between 0 to 34.0.

Calicut Airport: Inside the airport, during Aedes vector surveillance from 2015 to 2019, the premise index (PI) ranged between 0 to 15.4 with Container Index $(\mathrm{Cl})$ ranged from 0 to 5.4 and Breteau index has been between 0 to 15.4. Outside the airport, the house index $(\mathrm{HI})$ ranged between 0.0 to 10.7 with Container Index $(\mathrm{Cl})$ ranged from 0.0 to 11.8 and Breteau index has been between 0.0 to 14.0.

Jaipur Airport: Inside the airport, during Aedes vector surveillance from 2015 to 2019, the premise index (PI) ranged between 0.0 to 17.3 with Container Index $(\mathrm{Cl})$ ranged from 0.0 to 1.1 and Breteau index has been between 0.0 to 21.7. Outside the airport, the house index (HI) ranged between 0.0 to 9.0 with Container Index $(\mathrm{Cl})$ ranged from 0.0 to 7.6 and Breteau index has been between 0.0 to 9.0.

New Mangalore Airport: Inside the airport, during Aedes vector surveillance from 2015 to 2019, the premise index (PI) ranged between 0.0 to 4.3 with Container Index (CI) ranged from 0.0 to 3.6 and Breteau index has been between 0.0 to 8.7. Outside the airport, the house index $(\mathrm{HI})$ ranged between 0.0 to 5.0 with Container Index $(\mathrm{Cl})$ ranged from 0.0 to 19.4 and Breteau index has been between 0.0 to 9.0.
Tirupati Airport: Inside the airport, during Aedes vector surveillance from 2015 to 2019, the premise index (PI) ranged between 0.0 to 11.1 with Container Index $(\mathrm{Cl})$ ranged from 0.0 to 1.4 and Breteau index has been between 0.0 to 11.1. Outside the airport, the house index $(\mathrm{HI})$ ranged between 18.2 to 62.5 with Container Index $(\mathrm{Cl})$ ranged from 2.8 to 9.9 and Breteau index has been between 27.3 to 150.0.

Bangalore Airport: Inside the airport, during Aedes vector surveillance from 2015 to 2019, the premise index (PI) ranged between 5.1 to 12.0 with Container Index $(\mathrm{Cl})$ ranged from 0.96 to 10.2 and Breteau index has been between 6.38 to 82.50 Outside the airport, the house index $(\mathrm{HI})$ ranged between 0 to 89.5 with Container Index $(\mathrm{Cl}$ ) ranged from 0 to 13.6 and Breteau index has been between 0 to 52.3.

Trichy Airport: Inside the airport, during Aedes vector surveillance from 2015 to 2019, the premise index (PI) ranged between 0 to 14.3 with Container Index $(\mathrm{Cl})$ ranged from 0 to 25.0 and Breteau index has been between 0 to 14.3. Outside the airport, the house index $(\mathrm{HI})$ ranged between 3.4 to 12.6 with Container Index $(\mathrm{Cl})$ ranged from 2.7 to 7.9 and Breteau index has been between 4.9 to 17.3.

The status of compiled reports on post-monsoon vector surveillance after the visits at POE's of International Airports during 2015-2020 is given in Table 2.

Amritsar Airport: The entomological indices i.e. $\mathrm{PI}, \mathrm{Cl}$ and BI have been zero inside the airport from 2015 to 2017. However, House Index (HI), Container Index (Cl) and Breteau 
Table 2.Compiled Data of Entomological Indices Recorded from Different Airports during Post-monsoon (20 I5-2020)

\begin{tabular}{|c|c|c|c|c|c|c|c|}
\hline \multirow{3}{*}{ Name of airport } & \multirow{3}{*}{ Year } & \multicolumn{6}{|c|}{ Post-monsoon } \\
\hline & & \multicolumn{3}{|c|}{ Entomological indices (Inside) } & \multicolumn{3}{|c|}{ Entomological indices (Outside) } \\
\hline & & PI & $\mathrm{Cl}$ & BI & HI & $\mathrm{Cl}$ & BI \\
\hline \multirow{6}{*}{ Amritsar Airport } & 2015 & 0 & 0 & 0 & 0 & 0 & 0 \\
\hline & 2016 & 0 & 0 & 0 & 0 & 0 & 0 \\
\hline & 2017 & 0.0 & 0.0 & 0.0 & 6.0 & 4.4 & 6.0 \\
\hline & 2018 & 18.2 & 20.8 & 90.9 & 2.4 & 4.8 & 3.8 \\
\hline & 2019 & 15.2 & 13.9 & 52.2 & 6.0 & 6.1 & 11.0 \\
\hline & 2020 & \multicolumn{6}{|c|}{ Not Done due to COVID-19 } \\
\hline \multirow{6}{*}{$\begin{array}{c}\text { Thiruvanthpuram } \\
\text { Airport }\end{array}$} & 2015 & 14.58 & 11.05 & 41.67 & 12.0 & 3.60 & 12 \\
\hline & 2016 & 3.7 & 0.6 & 3.7 & 5.0 & 3.8 & 5.0 \\
\hline & 2017 & 10.2 & 20.5 & 69.4 & 6.0 & 2.4 & 7.0 \\
\hline & 2018 & 6.0 & 14.3 & 16.0 & 4.0 & 5.1 & 4.0 \\
\hline & 2019 & 2.6 & 5.2 & 2.6 & 3.0 & 7.8 & 3.0 \\
\hline & 2020 & 2.7 & 25.0 & 2.7 & 4.0 & 11.3 & 6.0 \\
\hline \multirow{6}{*}{ Goa Airport } & 2015 & 0 & 21.4 & 0 & 0 & 12 & 0 \\
\hline & 2016 & Not Done & & & & & \\
\hline & 2017 & Not Done & & & & & \\
\hline & 2018 & 6.5 & 4.4 & 6.5 & 4.6 & 3.0 & 5.3 \\
\hline & 2019 & 3.4 & 2.3 & 3.4 & 8.7 & 13.0 & 11.9 \\
\hline & 2020 & \multicolumn{6}{|c|}{ Not Done due to COVID-19 } \\
\hline \multirow{6}{*}{ Cochin Airport } & 2015 & 11.76 & 1.21 & 11.76 & - & 4.12 & - \\
\hline & 2016 & 5.9 & 8.3 & 5.9 & 4.0 & 6.6 & 4.0 \\
\hline & 2017 & 7.1 & 16.7 & 7.1 & 3.0 & 6.2 & 3.0 \\
\hline & 2018 & 0.0 & 0.0 & 0.0 & 8.0 & 13.7 & 10.0 \\
\hline & 2019 & 13.5 & 15.8 & 24.3 & 5.0 & 6.6 & 5.0 \\
\hline & 2020 & 0 & 0 & 0 & 1.0 & 2.4 & 1.0 \\
\hline \multirow{4}{*}{ Calicut Airport } & 2017 & 15.0 & 24.7 & 100.0 & 3.3 & 3.6 & 3.3 \\
\hline & 2018 & 2.0 & 4.3 & 6.1 & 5.9 & 11.7 & 5.9 \\
\hline & 2019 & 16.6 & 11.4 & 33.3 & 6.0 & 9.8 & 7.0 \\
\hline & 2020 & \multicolumn{6}{|c|}{ Not Done due to COVID-19 } \\
\hline \multirow{4}{*}{ Jaipur Airport } & 2017 & $\begin{array}{c}\text { New Airport included } \\
\text { in year } 2018 \\
\end{array}$ & & & & & \\
\hline & 2018 & 37.0 & 12.0 & 48.0 & 24.0 & 28.0 & 34.0 \\
\hline & 2019 & 8.7 & 9.5 & 21.7 & 25.2 & 14.7 & 36.9 \\
\hline & 2020 & \multicolumn{6}{|c|}{ Not Done due to COVID-19 } \\
\hline \multirow{4}{*}{$\begin{array}{c}\text { New Mangalore } \\
\text { Airport }\end{array}$} & 2017 & $\begin{array}{c}\text { New Airport included } \\
\text { in year } 2018\end{array}$ & & & & & \\
\hline & 2018 & 4.8 & 1.5 & 4.8 & 7.8 & 33.3 & 10.4 \\
\hline & 2019 & 19.4 & 9.6 & 57.1 & 6.8 & 16.7 & 7.7 \\
\hline & 2020 & \multicolumn{6}{|c|}{ Not Done due to COVID-19 } \\
\hline
\end{tabular}




\begin{tabular}{|c|c|c|c|c|c|c|c|}
\hline \multirow{4}{*}{ Tirupati Airport } & 2017 & $\begin{array}{c}\text { New Airport included } \\
\text { in year } 2018\end{array}$ & & & & & \\
\hline & 2018 & 30.7 & 8.9 & 38.5 & 70.0 & 21.4 & 240.0 \\
\hline & 2019 & 42.9 & 6.9 & 71.4 & 33.3 & 6.4 & 58.3 \\
\hline & 2020 & \multicolumn{6}{|c|}{ Not Done due to COVID-19 } \\
\hline \multirow{4}{*}{ Bangalore Airport } & 2017 & 7.6 & 7.6 & 21.5 & 15.5 & 4.6 & 17.8 \\
\hline & 2018 & 2.8 & 0.8 & 2.8 & 16.0 & 5.9 & 24.0 \\
\hline & 2019 & 6.0 & 1.1 & 9.6 & 16.1 & 5.5 & 19.5 \\
\hline & 2020 & 11.3 & 9.5 & 2.2 & 0 & 0 & 0 \\
\hline \multirow{4}{*}{ Trichy Airport } & 2017 & $\begin{array}{c}\text { New Airport included } \\
\text { in year } 2018\end{array}$ & & & & & \\
\hline & 2018 & 15.4 & 20.0 & 15.4 & 8.9 & 9.7 & 17.9 \\
\hline & 2019 & 9.1 & 5.9 & 9.1 & 40.2 & 24.6 & 64.9 \\
\hline & 2020 & 16.7 & 7.4 & 16.7 & 6.0 & 5.1 & 15.0 \\
\hline
\end{tabular}

Index (BI) have been 18.2, 15.2 and 13.9, 20.8 and 90.9, 52.2 in the years 2018 \& 2019 respectively. This may be due to the newly developed area and in the out skirt of the town and the residential areas have grown up near the airport now.

Thiruvanthapuram Airport: Inside the airport, during Aedes vector surveillance from 2015 to 2019, the premise index (PI) ranged between 2.6 to 14.58 with Container Index (CI) ranged from 0.6 to 25.0 and Breteau index has been between 2.6 to 69.4 . Outside the airport, the house index $(\mathrm{HI})$ ranged between 3.0 to 12.0 with Container Index $(\mathrm{Cl})$ ranged from 2.4 to 12.0 and Breteau index has been between 3.0 to 12.0 .

Goa Airport: Inside the airport, during Aedes vector surveillance from 2015 to 2019, the premise index (PI) ranged between 0.0 to 6.5 with Container Index $(\mathrm{Cl})$ ranged from 2.3 to 21.4 and Breteau index has been between 0.0 to 6.5. Outside the airport, the house index $(\mathrm{HI})$ ranged between 0.0 to 8.7 with Container Index $(\mathrm{Cl})$ ranged from 3.0 to 13.0 and Breteau index has been between 0.0 to 11.9 .

Cochin Airport: Inside the airport, during Aedes vector surveillance from 2015 to 2019, the premise index (PI) ranged between 0.0 to 13.5 with Container Index $(\mathrm{Cl})$ ranged from 0.0 to 16.7 and Breteau index has been between 0.0 to 24.3. Outside the airport, the house index $(\mathrm{HI})$ ranged between 1.0 to 8.0 with Container Index $(\mathrm{Cl})$ ranged from 2.4 to 13.7 and Breteau index has been between 1.0 to 10.0.

Calicut Airport: Inside the airport, during Aedes vector surveillance from 2015 to 2019, the premise index (PI) ranged between 2.0 to 16.6 with Container Index $(\mathrm{Cl})$ ranged from 4.3 to 24.7 and Breteau index has been between 6.1 to 100.0 . Outside the airport, the house index $(\mathrm{HI})$ ranged between 3.3 to 6.0 with Container Index $(\mathrm{Cl})$ ranged from 3.6 to 11.7 and Breteau index has been between 3.3 to 7.0.

Jaipur Airport: Inside the airport, during Aedes vector surveillance from 2015 to 2019, the premise index (PI) ranged between 8.7 to 37.0 with Container Index $(\mathrm{Cl})$ ranged from 9.5 to 12.0 and Breteau index has been between 21.7 to 48.0. Outside the airport, the house index $(\mathrm{HI})$ ranged between 24.0 to 25.2 with Container Index $(\mathrm{Cl})$ ranged from 14.7 to 28.0 and Breteau index has been between 34.0 to 36.9 .

New Mangalore Airport: Inside the airport, during Aedes vector surveillance from 2015 to 2019, the premise index (PI) ranged between 4.8 to 19.4 with Container Index $(\mathrm{CI})$ ranged from 1.5 to 9.6 and Breteau index has been between 4.8 to 57.1 . Outside the airport, the house index $(\mathrm{HI})$ ranged between 6.8 to 7.8 with Container Index $(\mathrm{Cl})$ ranged from 16.7 to 33.3 and Breteau index has been between 7.7 to 10.4 .

Tirupati Airport: Inside the airport, during Aedes vector surveillance from 2015 to 2019, the premise index (PI) ranged between 30.7 to 42.9 with Container Index (Cl) ranged from 6.9 to 8.9 and Breteau index has been between 38.5 to 71.4. Outside the airport, the house index $(\mathrm{HI})$ ranged between 33.3 to 70.0 with Container Index $(\mathrm{Cl})$ ranged from 6.4 to 21.4 and Breteau index has been between 58.3 to 240.0 .

Bangalore Airport: Inside the airport, during Aedes vector surveillance from 2015 to 2019, the premise index (PI) ranged between 2.8 to 11.3 with Container Index $(\mathrm{Cl})$ ranged from 0.8 to 9.5 and Breteau index has been between 2.2 to 21.5. Outside the airport, the house index (HI) ranged between 0.0 to 16.1 with Container Index $(\mathrm{Cl})$ ranged from 0.0 to 5.9 and Breteau index has been between 0.0 to 24.0.

Trichy Airport: Inside the airport, during Aedes vector surveillance from 2015 to 2019, the premise index (PI) ranged between 9.1 to 16.7 with Container Index $(\mathrm{Cl})$ ranged from 5.9 to 20.0 and Breteau index has been between 9.1 to 16.7. Outside the airport, the house index ( $\mathrm{HI}$ ) ranged between 6.0 to 40.2 with Container Index $(\mathrm{Cl})$ ranged from 
5.1 to 24.6 and Breteau index has been between 15.0 to 64.9.

\section{Discussion}

It has been observed that the entomological indices have been quite high at the Thiruvanthapuram, Cochin, Bangalore, Trichy and Tirupati International airports, though Aedes breeding was also found at other airports as well in different years during the visits by the surveillance teams. Dengue vector has been found to prefer for breeding in small receptacles comprised of earthen pots, cement, metallic, plastic and rubber etc. Though plastic containers were also found retaining water, but the rubber containers were found to be most preferred habitats for Aedes breeding. It is important to note that Aedes albopictus has also been found to play role in the dengue transmission in southern states ${ }^{10}$ Therefore, local health authorities should also undertake appropriate control measures particularly in the surrounding areas of airports. There has been increase in the number of breeding sites in the post monsoon period inside those international airports, where the proper monitoring and surveillance has not been properly done with timely source reduction drive to eliminate mother foci by the concerned authorities. The other contributing factors is presence of breeding potential areas around the airport in the perimeter areas of 400 meters. The local geographical and climatic conditions are the contributing factors in view of the prolonged rainfall and presence of breeding potential sites. The local airport health authorities should undertake regular vector surveillance and control activities as per the guidelines provided through IHR (2005). The common breeding habitats for aedes aegypti inside and outside the airports usually comprised on solid waste dumping areas comprising of iron, cement, steel, plastic, earthen, tyres, glass and paper etc. In case, the containers holding small quantity of water is present in the premised, Aedes breeding may spill over to these containers. International Health Regulations (IHR), 1969 emphasized that the concerned National and State Government must keep International Airports \& Seaports free from Aedes aegypti, the vector of Dengue/Zika/Chikunguniya/Yellow fever. The junk yards inside the airports and the residential areas in the perimeter area of airports may provide congenial conditions for breeding of Aedes aegypti mosquito.

\section{Conclusion}

On the basis of key findings by the surveillance teams, it can be concluded that the regular and timely monitoring of Aedes aegypti vector is essential at appropriate entry points for timely planning and implementing the appropriate control measures. This would lead to prevent any future invasion of new pathogen of public health concern. The local airport health authorities are responsible to undertake regular vector surveillance activities inside the airport and around the airports in coordination with the district health teams to maintain zero tolerance of Aedes vector breeding as per IHR (2005) regulations.

\section{Conflict of Interest: None}

\section{References}

1. World Health Organization. International Health Regulations. Third Annotated Edition. WHO/HQ, Geneva. 1983.

2. International travel and health. Geneva: World Health Organization. 2002.

3. Soper FL, Wilson DB, Lima Antunes WS. The organization permanent nation-wide anti-Aedes aegypti measures in Brazil. New York: The Rockefeller Foundation, 1943. p.1-13.

4. Kaul SM, Sharma RS, Sharma SN, Panigrahi N, Phukan PK, Shiv L. Preventing Dengue and DHF. The role of entomological surveillance. J Commun Dis. 1998 Sep;30(3):187-92. [PubMed] [Google Scholar]

5. Sharma SN, Raina VK, Kumar A. Dengue/DHF: an emerging disease in India. J Commun Dis. 2000 Sep;32(3):175-9. [PubMed] [Google Scholar]

6. Kamal S, Patnaik SK, Sharma SK, Rao JS. A study on the breeding habitats of Aedes Species around Visakhapatnam sea port. J Commun Dis. 2003 Mar;35(1):52-5. [PubMed] [Google Scholar]

7. Das BP, Sharma SK, Dutta KK. Prevalence of Aedes aegypti at the International Port Airport, Kolkata (West Bengal), India. Dengue Bulletin. 2000;24:124-6. [Google Scholar]

8. Sharma SN, Kumar S, Das BP, Thomas TG, Kumar K, Katyal R, Gill KS, Bora D, Lal S, Saxena VK. Entomological indices of Aedes aegyptiat some International Airports and seaports of Southern India-A Report. J Commun Dis. 2005 Sep;37(3):173-81. [PubMed] [Google Scholar]

9. Kumar K, Sharma A, Sarkar M, Chauhan A and Sharma R. Surveillance of Aedes aegypti (L) mosquitoes in Mumbai International Seaport (India) to monitor potential global health risks. J. Insects. 2014, p.1-5. [Google Scholar]

10. Das BP, Kabilan L, Sharma SN, Lal S, Regu K, Saxena VK. Detection of dengue virus in wild caught Aedes albopictus (Skuse) around Kozhikode Airport, Malappuram District, Kerala, India. Dengue Bulletin. 2004;28:210-2. [Google Scholar] 